\title{
The digital aqueous humor outflow meter: an alternative tool for screening of the human eye outflow facility
}

This article was published in the following Dove Press journal:

Clinical Ophthalmology

25 August 2010

Number of times this article has been viewed

\section{Vassilios P Kozobolis \\ Eleftherios I Paschalis \\ Nikitas C Foudoulakis \\ Stavrenia C Koukoula \\ Georgios Labiris}

Department of Ophthalmology and Eye Institute of Thrace, Democritus University of Thrace, Alexandroupolis, Greece
Correspondence: Eleftherios Paschalis llios Eye Institute of Thrace, University Hospital of Alexandroupolis, 68 I00 Dragana,Alexandroupolis, Thrace, Greece

$\mathrm{Tel}+302551076109$

Fax +30281030359

Email epaschalis@hotmail.com
Purpose: To develop, characterize, and validate a prototype digital aqueous humor outflow tonographer (DAHOM).

Material and methods: The DAHOM was developed, characterized, and validated in three phases. Phase 1 involved construction of the sensor. This was broadly based on the fundamental design of a typical Schiotz tonographer with a series of improvements, including corneal indentation, which was converted to an electrical signal via a linear variable differential transducer, an analog signal which was converted to digital via ADC circuitry, and digital data acquisition and processing which was made possible by a serial port interface. Phase 2 comprised development of software for automated assessment of the outflow facility. Automated outflow facility assessment incorporated a series of fundamental improvements in comparison with traditional techniques, including software-based filtering of ripple noise and extreme variations, rigidity impact analysis, and evaluation of the impact of patient age, central corneal thickness, and ocular axial length. Phase 3 comprised characterization and validation of DAHOM, for which we developed an experimental setup using porcine cadaver eyes. DAHOM's repeatability was evaluated by means of Cronbach's alpha and intraclass correlation coefficient. The level of agreement with a standard Schiotz tonographer was evaluated by means of paired $t$-tests and Bland-Altman analysis in human eyes.

Results: The experimental setup provided the necessary data for the characterization of DAHOM. A fourth order polynomial equation provided excellent fit (R square $>0.999$ ). DAHOM demonstrated high repeatability (Cronbach's alpha $\geq 0.997$; intraclass correlation coefficient $\geq 0.987$ ) and an adequate level of agreement with a standard Schiotz tonographer.

Conclusions: This study presents the development, characterization, and validation of a prototype digital tonographer. DAHOM demonstrates high repeatability and a sufficient level of agreement with a typical Schiotz tonographer, while its digital design remedies known vulnerabilities of conventional tonographers.

Keywords: glaucoma, tonography, pressure, outflow facility, aqueous humor

\section{Introduction}

The importance of aqueous humor tonography in research settings has been highlighted over many years. ${ }^{1-3}$ Tonography outcomes provide essential information for a series of ophthalmic diseases, eg, the glaucomas, and facilitate exploration of the ocular manifestations of systemic diseases. However, tonography in daily clinical settings has yet to be applied, mainly due to time constraints in hospital departments. Moreover, prevalent tonographic settings suffer from poor repeatability which limits their clinical usefulness. Among the primary causes of variability is the fact that reliable measurements require continuous eye alignment, which is 
difficult to achieve in practice. On the other hand, data collection and processing using traditional tonographers is difficult, because they do not provide digital output, automated assessment of the outflow facility, or evaluation of the impact of a series of known modifiers of the outflow facility. Within this context, we demonstrate here the development, characterization, and validation of a novel digital aqueous humor outflow topographer (DAHOM) that addresses the series of vulnerabilities of traditional tonographers.

\section{Materials and methods}

\section{Setting}

The study adhered to the tenets of the Declaration of Helsinki and written informed consent was given by all participants. This was a prospective study conducted in the Department of Ophthalmology at the University Hospital of Alexandroupolis in Greece between 2004 and 2007.

\section{Development of DAHOM}

The digital outflow meter was designed at the Eye Institute of Thrace, in collaboration with the Electrical Engineering Department of the Technical University of Thrace. The development of the system was done in three phases.

\section{Phase I}

Phase 1 included construction of the electromechanical system with the sensor and the electronic circuitry (Figure 1). The sensor design was broadly based on the fundamental design of a typical Schiotz tonographer. The sensor converted corneal indentation to electrical signal with high sensitivity $(1.719 \mathrm{mV} /$ volt/0.0254 mm) using a linear variable differential transducer. All elements were connected to an aluminum alloy frame capable of retraction and sterilization. Analog to digital signal conversion was accomplished using ADC electronic circuitry providing interface via a serial port (RS232, Figure 2).

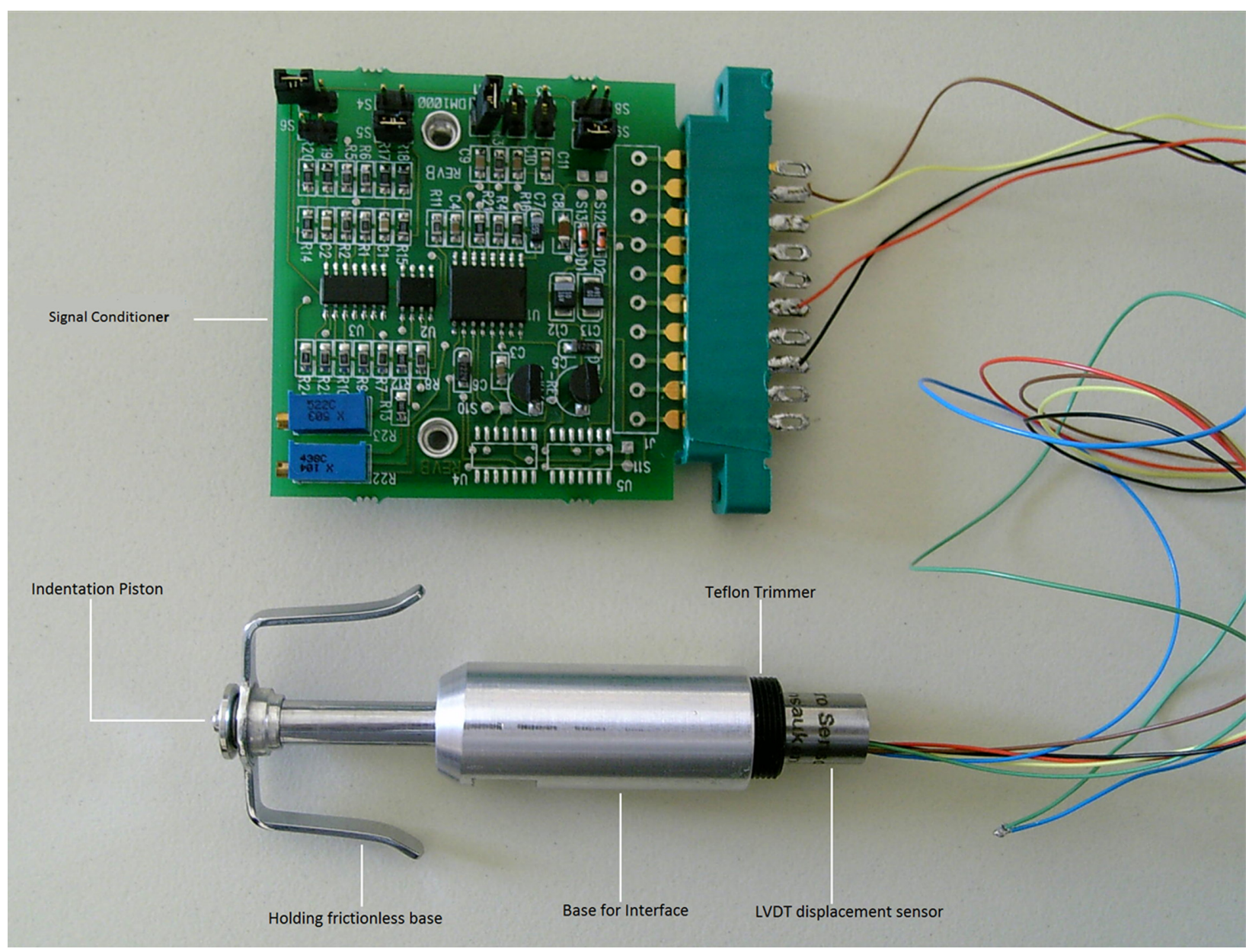

Figure I Digital outflow meter, including linear variable differential transducer and signal conditioner circuit.

The digital outflow transducer with the contact tip (indentation piston), the base (center), and the linear variable differential transducer sensor (right). Connector cables are used for power supply and data transfer to the DAQ board. The signal conditioning board is responsible for sinusoidal wave generation, signal rectification, and phasesensitive demodulation processing. 


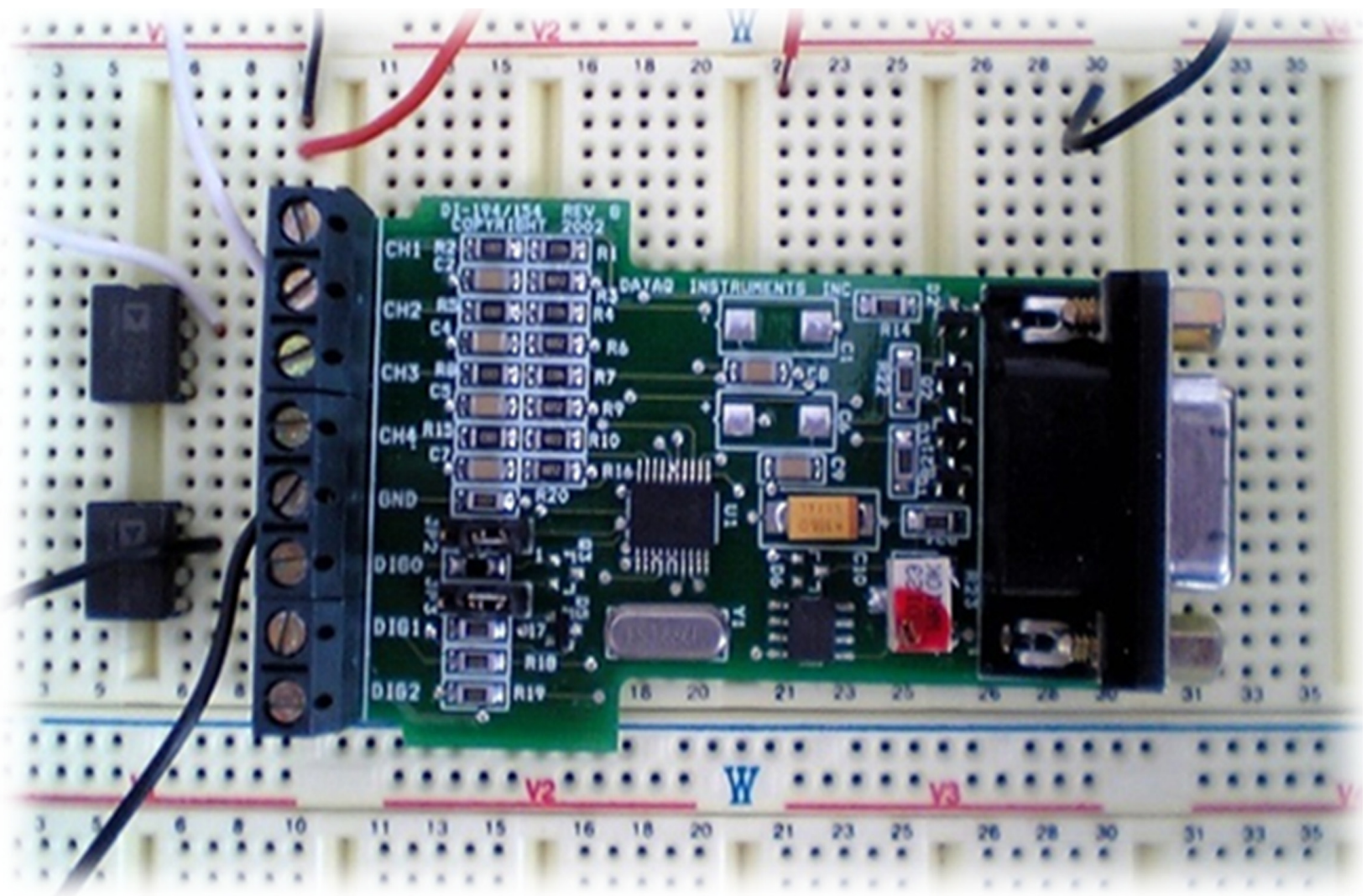

Figure 2 Data acquisition board with analog to digital converter and serial communication with a PC.

Electronic circuitry with data acquisition, analog to digital converter, and RS 232 communication interface.

\section{Phase 2}

Phase 2 involved development of the software and the conversion algorithm for the evaluation of the outflow facility. A software-based percentile filter was used to cut out ripple noise and random measurement variations (Figure 3). Observed differences in intraocular pressure (IOP) measurements between the DAHOM and Goldmann applanation tonometer (GAT) were used for assessment of ocular rigidity.

The outflow facility was calculated according to the following formula:

$$
\begin{aligned}
C_{\text {out }}= & \frac{\Delta V}{\left(\frac{P_{t 0}+P_{t 4}}{2}-P_{\text {applanation }}-\Delta P_{\text {indentation }}\right) \cdot 4} \\
& =\frac{\left(V_{C 4}-V_{C 0}\right)+\frac{1}{K} \log \left(\frac{P_{t 0}}{P_{t 4}}\right)}{\left(\frac{P_{t 0}+P_{t 4}}{2}-P_{\text {applanation }}-\Delta P_{\text {indentation }}\right) \cdot 4}
\end{aligned}
$$

where $V_{C 4}-V_{C 0}$ is the corneal volume displacement during the tonography study, $\mathrm{K}$ is the sclera rigidity factor or ocular rigidity factor, $P_{t 0} / P_{t 4}$ is the hydrostatic pressure difference between the points of flow resistance, $P_{\text {applanation }}$ is the IOP measured by GAT, $\Delta P$ is the mechanical increase of IOP from the weight of the tonographer, and 4 is duration of the study in minutes. ${ }^{4}$

A software program was developed in Java language, capable of calculating the outflow facility (Figure 4). Rigidity impact analysis was incorporated in the software algorithm using GAT IOP measurement, as suggested by Friedenwald. ${ }^{4}$

The following formula was used to calculate rigidity:

$$
\begin{aligned}
\text { Rigidity }= & 4.5282 E^{-5}+6.7443 E^{-4} X+6.165 E^{-6} X^{2} \\
& -2.18104 E^{-7} X^{3}-2.07212 E^{-8} X^{4}+2.7598 E^{-9} X^{5} \\
& -1.1391 E^{-10} X^{6}+2.26627 E^{-12} X^{7} \\
& -2.20326 E^{-14} X^{8}+8.45107 E^{-17} X^{9}
\end{aligned}
$$

where $X$ is the mathematical arc tangent operator of the difference between the applanation and the indentation IOP, while the following three formulas (F1-F3) were used to define the indentational versus IOP measurement for 5.5, 7.5 , and $10 \mathrm{~g}$ weight of the digital outflow meter:

$$
\begin{aligned}
I O P_{\text {indent }}^{5.5 g}= & 51.081-5.887 x+0.479 x^{2} \\
& -0.0215 x^{3}+3.832 E^{-4} x^{4}
\end{aligned}
$$



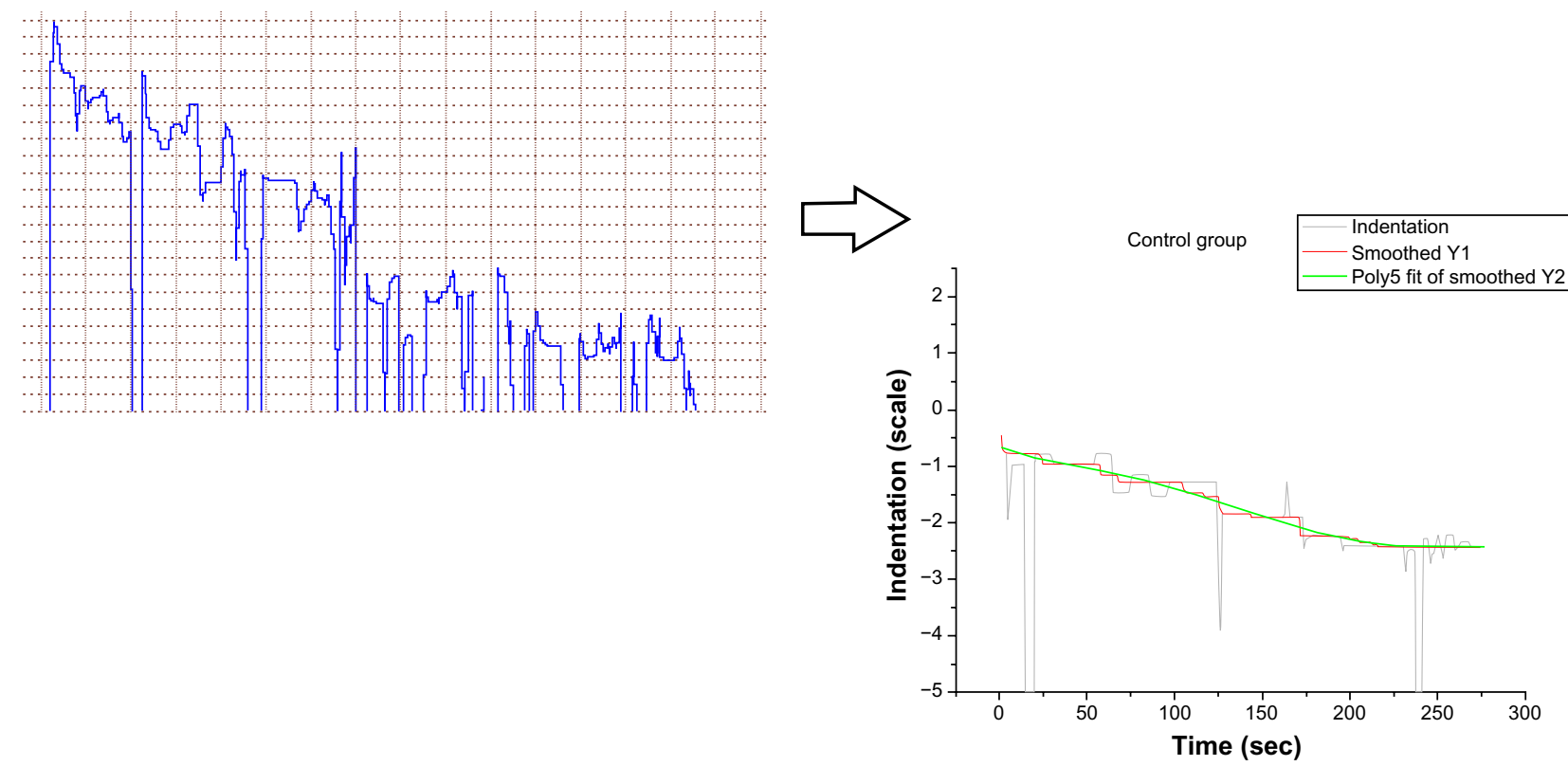

Figure 3 Data filtering and tonographic polynomial fit.

Data as recorded in real time by the data acquisition system (left graph) and data post-study analysis with digital filtering (red line) and polynomial fit (green line, right graph).

$$
\begin{aligned}
I O P_{\text {indent }}^{7.5 g}= & 69.668-8.045 x+0.655 x^{2} \\
& -0.029 x^{3}+5.204 E^{-4} x^{4} \\
I O P_{\text {indent }}^{10 g}= & 92.89-10.717 x+0.872 x^{2} \\
& -0.039 x^{3}+6.937 E^{-4} x^{4}
\end{aligned}
$$

where $x$ is the magnitude of indentation for the digital tonographer in $\mathrm{mm}$.

A series of optional parameters were also incorporated in the algorithm in order to correct the rigidity measurements

based on the influence of several biomechanical factors, including central cornea thickness, age of patient, and ocular axial length (Figure 4). These formulae were derived from previously published studies on ocular rigidity variation. ${ }^{5,6}$

$$
\begin{aligned}
K_{\text {age }}= & 0.00526+1.09285 E^{-4} \times A g e \\
K_{c c t}= & -0.02055+6.33781 E^{-5} \cdot C C T \\
K_{\text {refraction }}= & 0.02056+6.6158 E^{-4} L+2.0559 E^{-5} L^{2} \\
& +9.70044 E^{-7} L^{3}+1.6981 E^{-8} L^{4}
\end{aligned}
$$

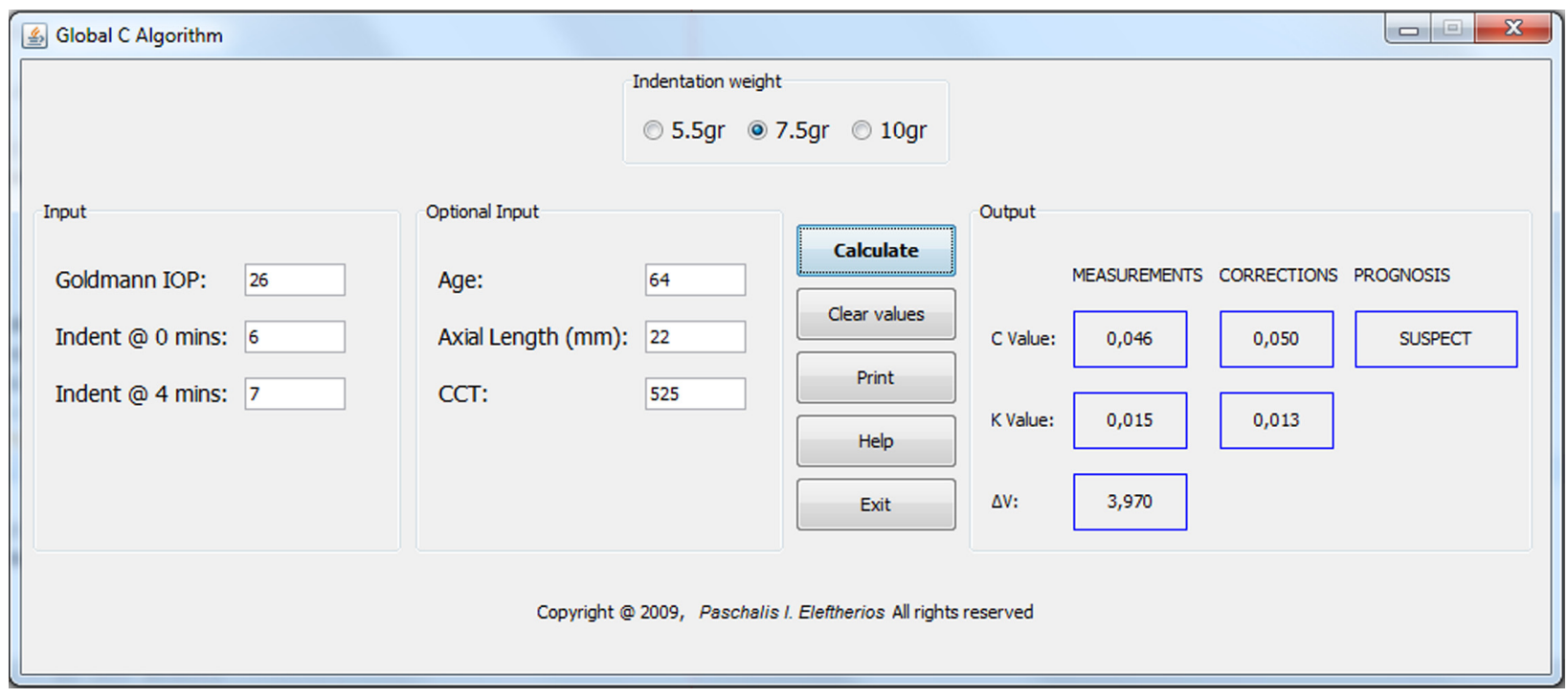

Figure 4 Outflow facility windows software based on Java language.

Outflow facility calculation software, designed in Java programming language with Windows ${ }^{\circledR}$ interface environment. Mandatory "inputs" are designed to measure the outflow facility, while "optional" inputs are designed to measure the ocular rigidity factor. "Corrected" outputs represent the outflow facility and rigidity measurements, corrected by the "optional" inputs. Correlation is a predictive algorithm of the severity of the condition from 0 to 3 for normal to acute angle closure, respectively. 
where $K_{\text {age }}$ is the rigidity variation based on the age of the patient; ${ }^{5} K_{c c t}$ is the rigidity variation based on central cornea thickness; ${ }^{4} K_{\text {refraction }}$ is the rigidity variation based on the ocular axial length; ${ }^{4}$ age is patient age in years; $\mathrm{CCT}$ is the central corneal thickness $(\mu \mathrm{m})$; and $\mathrm{L}$ is the ocular axial length $(\mathrm{mm})$.

\section{Phase 3}

Phase 3 involved characterization and validation of the DAHOM. Characterization of the tonometer was accomplished using porcine cadaver eyes according to the following procedure. A microelectronic pressure sensor was implanted into the anterior chamber using a fine needle. A second needle was injected into the eye, connecting a water tank of balanced solution for IOP regulation, which was accomplished by altering the water tank height and thus affecting the hydrostatic pressure difference in the eye (Figures 5 and 6). Experimental IOP measurements were obtained in the range $5-90 \mathrm{mmHg}$, with a $1 \mathrm{mmHg}$ increment.
Validation of the system was accomplished by comparing the measurement outcomes of the DAHOM with the corresponding ones of a Schiotz tonographer in a population of 30 volunteers according to the following procedure. Outflow facility measurements were obtained in one eye using a Schiotz tonographer and in the fellow eye by the DAHOM. Within one week, the procedure was repeated in a crossover manner. All tonography measurements were obtained by the same experienced operator (NF) who ensured proper eye fixation. Before each measurement, the Schiotz tonographer was calibrated according to the manufacturer's instructions. GAT IOP measurements determined the indentation weight for both systems. For IOPs less than $30 \mathrm{mmHg}$, a $5.5 \mathrm{~g}$ weight was used, while a $7.5 \mathrm{~g}$ weight was used for IOP between 30 and $45 \mathrm{mmHg}$. For IOPs higher than $45 \mathrm{mmHg}$, a $10 \mathrm{~g}$ weight was used. The level of agreement between the two systems was evaluated by means of paired $t$-test and by Bland-Altman analysis. DAHOM repeatability was evaluated

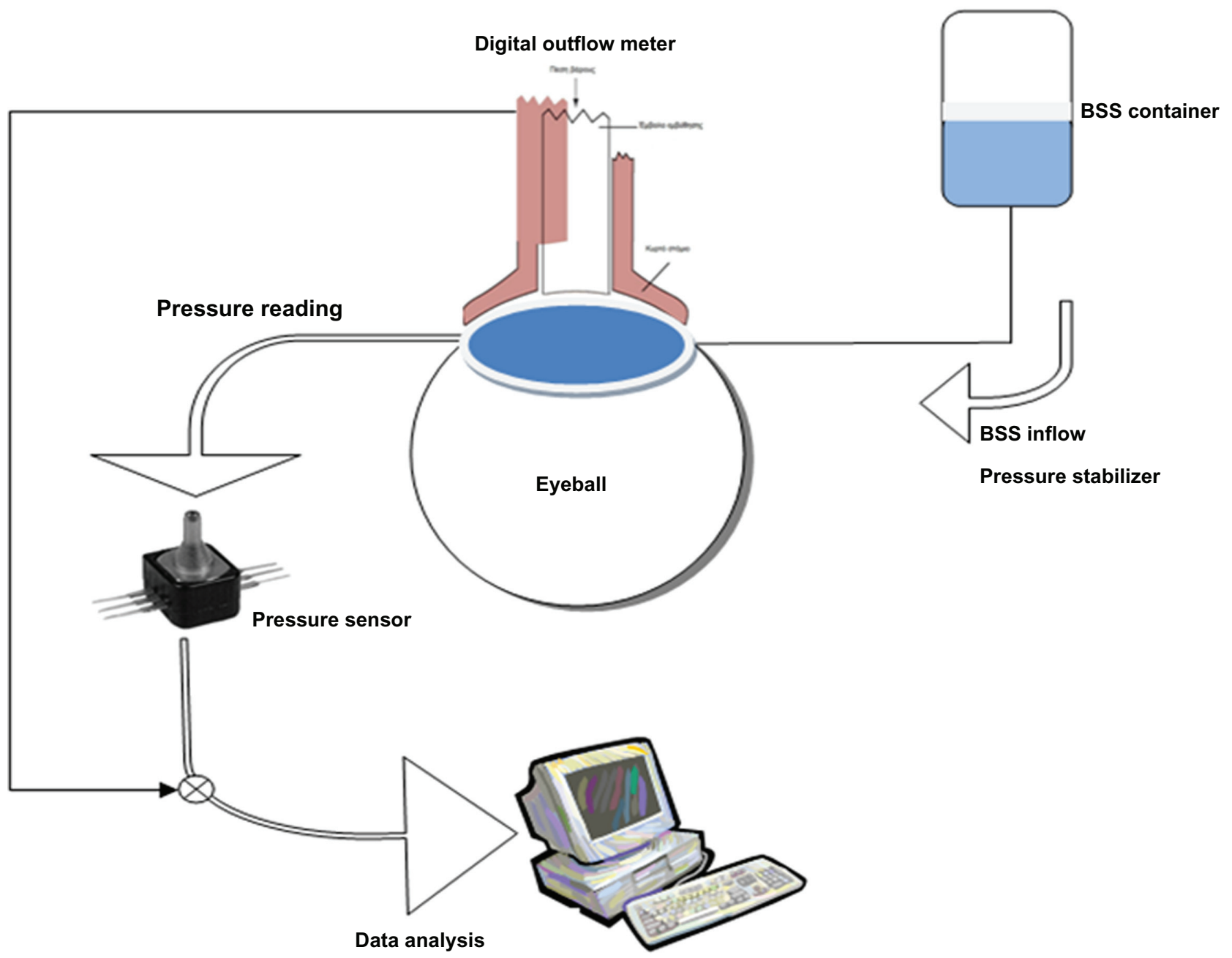

Figure $\mathbf{5}$ Laboratory setup for the characterization of the digital outflow meter.

Laboratory setup for the calibration of the system. The balanced solution (BSS) container is used for intraocular pressure regulation, the micropressure sensor is used for intracameral real-time intraocular pressure measurements, while the digital outflow meter performs tonography. All data are collected by the PC and analyzed. 


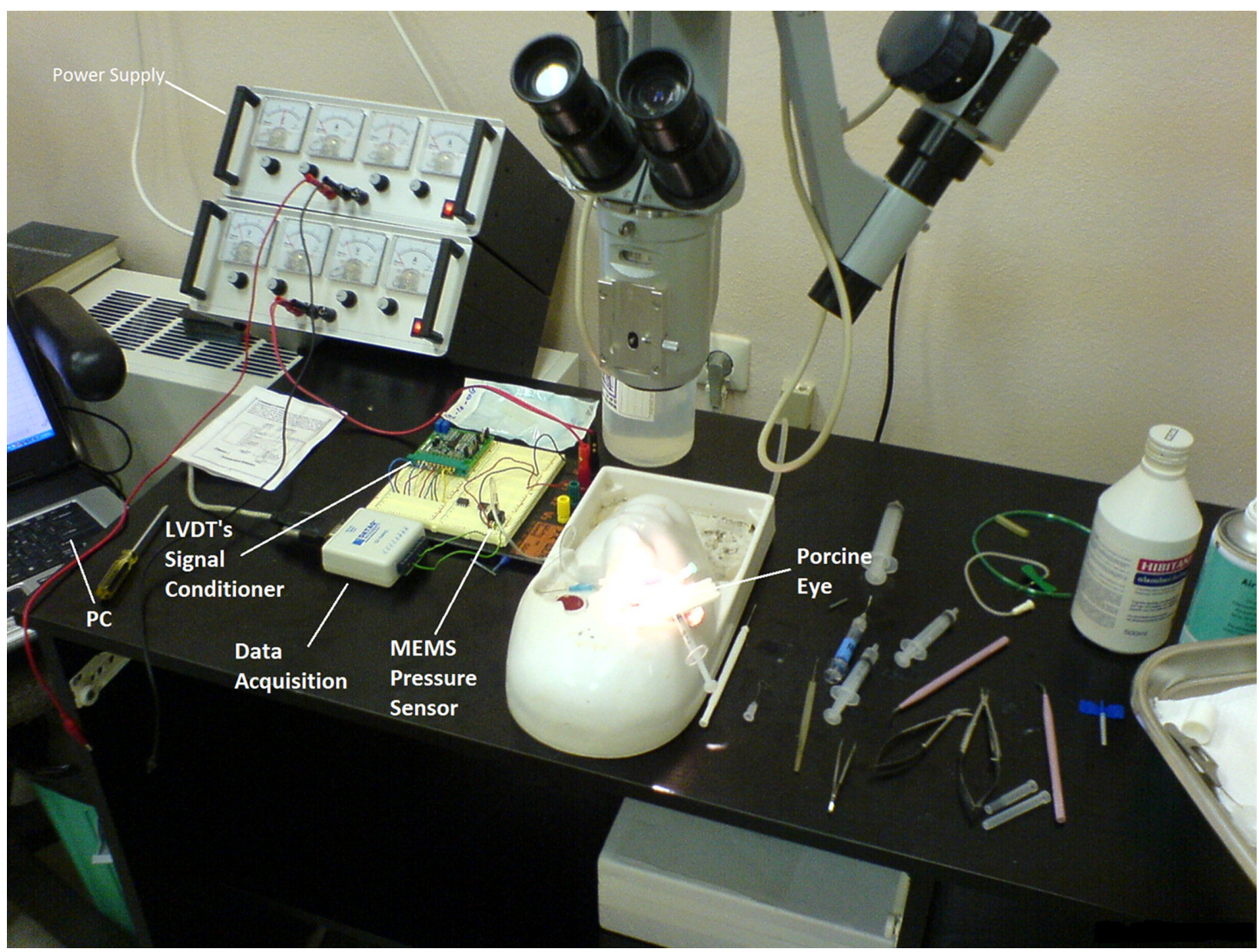

Figure 6 Experimental setup.

Experimental setup in porcine cadaver eyes using a microelectromechanic intracameral pressure sensor.

by both Cronbach's alpha test and the intraclass correlation coefficient (ICC) from three consecutive measurements prior to the tonography study.

\section{Statistical analysis}

Results were analyzed with the SPSS Version 17.0 (Statistical Package for the Social Sciences Inc., Chicago, IL). The normality of continuous variables was assessed using the Kolmogorov-Smirnov test. Quantitative variables expressed as mean \pm standard deviation (SD) and qualitative variables were expressed as frequencies and percentages. The MannWhitney test was used to assess outflow facility variations between the Schiotz and digital outflow meters. All tests were two-tailed, and statistical significance was considered as $P<0.05$. Intrasession repeatability was tested using Cronbach's alpha test and the ICC. Agreement of the outflow facility measurements between the digital and Schiotz outflow meters was assessed with Bland-Altman plots and 95\% limits of agreement. MedCalc version 9.0 software was used for the Bland-Altman plots.

\section{Results}

The experimental setup with the porcine eyes provided the necessary data for the characterization of the system's response, according to the following formulae:

$$
\begin{aligned}
I_{\text {IOP }}= & 51.081-117.735 x+191.649 x^{2} \\
& -171.753 x^{3}+61.131 x^{4} \\
I_{\text {MEMS }}= & 69.668-160.908 x+262.05 x^{2} \\
& -234.266 x^{3}+83.266 x^{4} \\
I_{\text {MEMS }}= & 92.89-214.339 x+348.911 x^{2} \\
& -312.038 x+111 x^{4}
\end{aligned}
$$

where $x$ is the magnitude of indentation for the DAHOM in $\mathrm{mm}$.

In fact, the characterization of the DAHOM was accomplished using a fourth order polynomial equation (adjusted R-square $>0.999$ in all polynomial fittings, Figure 7). Three different polynomial equations were derived, each one 


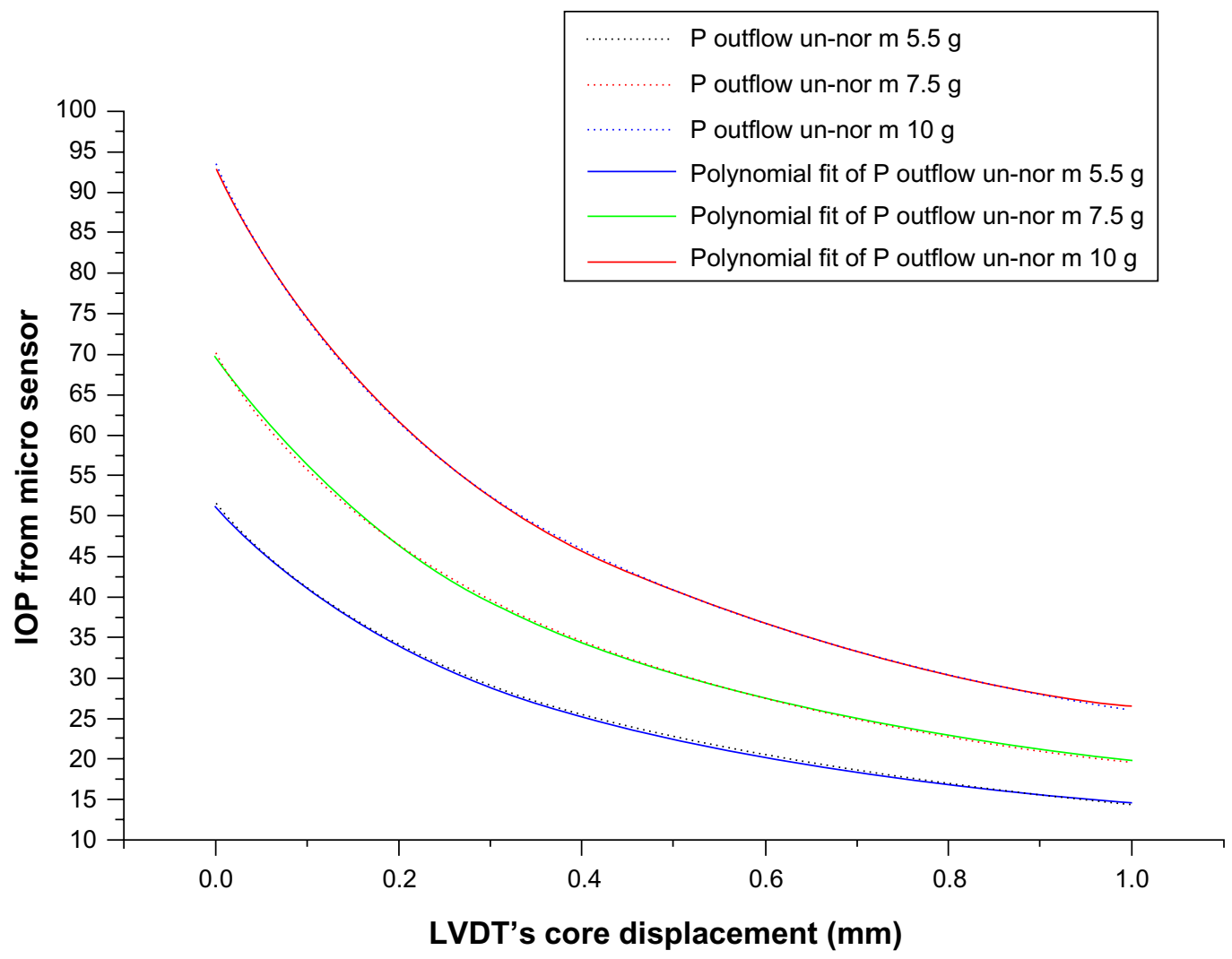

Figure 7 Indentation versus intraocular pressure intracameral readings from the microelectronic silicon-based pressure sensor.

Objective intraocular pressure versus indentation measurements in an experimental setup using extracted porcine cadaver eyes. Intraocular pressure measurements attained by a micropressure sensor, connected to the anterior chamber of the eye, while the indentation measurements attained by the digital outflow meter.

corresponding to a different plunger weight. Systems transfer functions are shown below. Equation F7 was used for a $5.5 \mathrm{~g}$ plunger weight, $\mathrm{F} 8$ for $7.5 \mathrm{~g}$, and F9 for $10 \mathrm{~g}$ :

$$
\begin{aligned}
y(x)= & 51.081-117.735 x+191.649 x^{2} \\
& -171.753 x^{3}+61.131 x^{4} \\
y(x)= & 69.668-160.908 x+262.05 x^{2} \\
& -234.266 x^{3}+83.266 x^{4} \\
y(x)= & 92.89-214.339 x+348.911 x^{2} \\
& -312.0 .8 x^{3}+111 x^{4}
\end{aligned}
$$

It should be mentioned that all polynomials were derived by assessment of the best fitting of the experimental results in a Cartesian plot, with one axis representing the experimental measurements of interest and the second axis representing the values obtained by the DAHOM. The order of polynomial fitting was selected in a way to provide R-Square adjustment higher than 0.98, ensuring minimum calculation error.

DAHOM demonstrated a sufficient level of agreement with the Schiotz tonographer. Specifically, the results for DAHOM were: $\mathrm{C}_{\text {Digital }} \pm \mathrm{SD}_{\text {Digital }}=0.168 \pm 0.08 \mu \mathrm{L} \times \mathrm{min}^{-1} \times \mathrm{mmHg}^{-1}$ and for the Schiotz tonometer were: $\mathrm{C}_{\text {schiotz }} \pm \mathrm{SD}_{\mathrm{s} \text {. }}$ chiotz $=0.163 \pm 0.09 \mu \mathrm{L} \times \mathrm{min}^{-1} \times \mathrm{mmHg}^{-1}$; Paired sample $t$-test validated measurements conformity $(P>0.12)$. Sufficient level of agreement was also confirmed by BlandAltman analysis. According to the plot in Figure 8, with the exception of two outlying values, the plot points are distributed in a symmetric manner about the "zero difference" line.

Regarding DAHOM's measurement repeatability, the Cronbach's alpha was 0.997 and the ICC was 0.987 , both tests suggesting high intrasession reliability.

\section{Discussion}

The objective of this study was to develop a digital aqueous humor tonographer that could provide valid information about the outflow facility and address a series of technical and design limitations of the conventional tonographers.

Various tonographers have been introduced during the past 60 years. First, Schiotz, ${ }^{7}$ then Bock et $\mathrm{al}^{8}$ and others ${ }^{9,10}$ introduced tonographers for measuring the outflow coefficient, and in 1951, Gant reported the use of an electronic tonographer connected to a paper strip. ${ }^{11}$ 


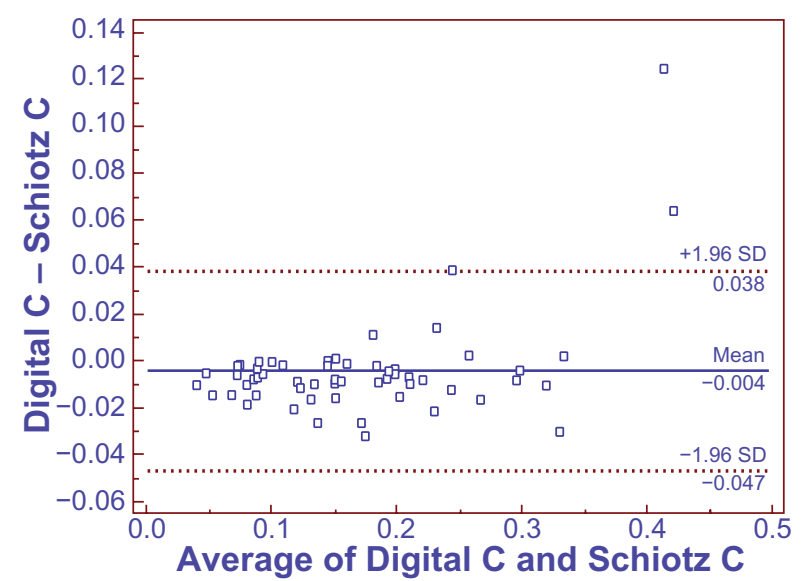

Figure 8 Bland-Altman plot showing interdevice difference plotted against mean measurements for each eye.

Bland-Altman plot showing interdevice difference plotted against mean measurements for each eye. Dotted line, zero line. Blue solid line, mean difference and boundaries of the $95 \%$ limits of agreement.

Among the difficulties in the development of a reliable tonographer is its characterization. For characterization of the DAHOM, we developed an experimental setup introducing an intracameral pressure sensor in porcine cadaver eyes. Although cadaver porcine eyes have biomechanical properties similar to those of human eyes, a number of differences should be taken into consideration, ie, cadaver eyes may introduce measuring errors due to lack of blood volume displacement during the tonography study, and despite similar stress-strain patterns, human and porcine corneas demonstrate different stress relaxation properties. ${ }^{12}$ However, neither of these differences interfered with the characterization or the validation process. In fact, both the Schiotz tonographer and DAHOM demonstrated very similar results in the majority of cases. The observed nonsignificant differences may well be attributable to the known Schiotz vulnerabilities regarding ocular rigidity assessment rather than to the design and/or implementation of the DAHOM project. ${ }^{13}$ Specifically, the average indentation values obtained by both systems (Schiotz and DAHOM) did not reveal any significant differences. However, the outcomes of the DAHOM are corrected by a series of rigidity impact algorithms (which is not the case for the Schiotz tonographer). Regarding outflow facility, the DAHOM demonstrated similar results in a series of former studies that used different tonographers. ${ }^{14-20}$

Regarding DAHOM's intrasession variability, both Cronbach's alpha and ICC tests suggested excellent repeatability. Specifically, the ICC value of 0.987 is well above the minimal ICC value of 0.90 that the literature suggests to be adequate.$^{21}$ It is known that in tonography studies the intrasession variability is exacerbated mainly due to the loss of eye alignment when retracting and placing the tonographer. In the software development of the DAHOM, we incorporated a software-based filter for automatic rejection of tracing irregularities that result in outlying values (Figure 3). However, hysteresis of the DAHOM was mainly attributed to the nonlinear semielastic properties of the eye, as shown in the report by Luce. ${ }^{22}$

Following the introduction of a reliable and valid tonographer like the DAHOM, its enhancements over the traditional tonographers should be underscored. The capability to provide raw data and outcomes measured in a digital format facilitates the processing and reprocessing of the data (both real-time and at a later time), allows introduction of different filters for cutting off measurement irregularities, and facilitates tonographic follow-up of patients because point-topoint comparisons can be made over time. The capability to calculate ocular rigidity and incorporate its impact on every single measurement on final measured outcome is a major advance over traditional designs that assume a mean ocular rigidity value for their calculations. Moreover, there is the capability to correct the measured outcome of the DAHOM by estimation of the impact of a series of optional ocular biomechanical factors and patient age.

In summary, in this report we present a characterization and validation of the DAHOM, a novel digital aqueous humor tonographer that attempts to address the known inherent vulnerabilities of the traditional tonographers. Addressing these vulnerabilities will allow the implementation of future relevant studies with high clinical significance in diseases with disrupted aqueous humor outflow, eg, the glaucomas. Among them are the qualitative outflow profile analysis that could provide detail information of the dynamic regulation of the outflow facility, ${ }^{23-26}$ and the development of a glaucoma risk assessment algorithm, capable of identifying preclinical patterns of glaucoma development.

\section{Disclosure}

The authors report no conflict of interest in this work.

\section{References}

1. Grant WM. Tonographic method for measuring the facility and rate of aqueous flow in human eyes. Arch Ophthal. 1950;44(2):204-214.

2. Grant WM. Clinical tonography. Trans Am Acad Ophthalmol Otolaryngol. 1951;55:774-781.

3. Grant WM. Clinical measurements of aqueous outflow. AMA Arch Ophthalmol. 1951;46(2):113-131.

4. Friedenwald JS. Tonometer calibration; an attempt to remove discrepancies found in the 1954 calibration scale for Schiotz tonometers. Trans Am Acad Ophthalmol Otolaryngol. 1955;61:108.

5. Friedenwald JS. Contribution to the theory and practice of tonometry. Am J Opthalmol. 1937;20:985. 
6. Pallikaris IG, Kymionis GD, Ginis HS, Kounis GA, Tsilimbaris MK. Ocular rigidity in living human eyes. Invest Ophthalmol Vis Sci. 2005;46(2):409-414.

7. Schiotz HJ. Tonometrie. Arch F Augenh. 1909;63:317.

8. Bock J, Kronfeld PC, Stough JT. Effect on intraocular tension of corneal massage with the tonometer of Schiotz. AMA Arch Ophthalmol. 1934;11:796

9. Smith P. Quoted in Bock J, Kronfeld PC, Stough JT. Ophth Rev. 1915;34:65.

10. Wegner NV. Quoted by Bock J, Kronfeld PC, Stough JT. Ztschr F Augenh. 1925;55:381.

11. Helmick ED, Schie HG, Spencer RW. Tonography in the clinical management of glaucoma. AMA Arch Ophthalmol. 1956;56(6): 797-818.

12. Zeng Y, Yang J, Huang K, Lee Z, Lee X. A comparison of biomechanical properties between human and porcine cornea. J Biomech. 2001; 34(4):533-537.

13. Anderson DR, Grant WM. Re-evaluation of the Schiotz tonometer calibration. Invest Ophthalmol. 1970;9(6):430-446.

14. Feghali JG, Azar DT, Kaufman PL. Comparative aqueous outflow facility measurements by pneumatonography and Schiotz tonography. Invest Ophthalmol Vis Sci. 1986;27(12):1776-1780.

15. Hayashi M, Yablonski ME, Mindel JS. Methods for assessing the effects of pharmacologic agents on aqueous humor dynamics. In: Tasman W, Jaeger EA, editors. Duane's Foundations of Clinical Ophthalmology. Philadelphia, PA: Lippincott; 1993.

16. Yablonski ME, Cook DJ, Gray J. A fluorophotometric study of the effect of argon laser trabeculoplasty on aqueous humor dynamics. Am J Ophthalmol. 1985;99(5):579-582.
17. Toris CB, Koepsell SA, Yablonski ME, Camras CB. Aqueous humor dynamics in ocular hypertensive patients. J Glaucoma. 2002;11(3): 253-258.

18. Yablonski ME, Zimmerman TJ, Waltman SR, Becker B. A fluorophotometric study of the effect of topical timolol on aqueous humor dynamics. Exp Eye Res. 1978;27(2):135-142.

19. Hayashi M, Yablonski ME, Novack GD. Trabecular outflow facility determined by fluorophotometry in human subjects. Exp Eye Res. 1989;48(5):621-625.

20. Toris CB, Zhan G, Fan S, et al. Effects of travoprost on aqueous humor dynamics in patients with elevated intraocular pressure. J Glaucoma. 2007;16(2):189-195.

21. Portney LG, Watkins MP. Foundations of Clinical Research; Applications to Practice. 2nd ed. Upper Saddle River, NJ: Prentice-Hall; 2000.

22. Luce DA. Determining in vivo biomechanical properties of the cornea with an ocular response analyzer. J Cataract Refract Surg. 2005;31: $156-162$.

23. Drance SM. Correlation between optic disc changes and visual field defects in chronic open-angle glaucoma. Trans Am Acad Ophthalmol Otolaryngol. 1976;81(2):224-226.

24. Hoskins HD Jr, Gelber EC. Optic disk topography and visual field defects in patients with increased intraocular pressure. Am JOphthalmol. 1975;80(2):284-290.

25. Hitchings RA, Spaeth GL. The optic disc in glaucoma II: Correlation of the appearance of the optic disc with the visual field. Br J Ophthalmol. 1977;61(2):107-113.

26. Susanna R, Drance SM. Use of discriminant analysis I. Prediction of visual field defects from features of the glaucoma disc. Arch Ophthalmol. 1978;96(9):1568-1570.
Clinical Ophthalmology

\section{Publish your work in this journal}

Clinical Ophthalmology is an international, peer-reviewed journal covering all subspecialties within ophthalmology. Key topics include: Optometry; Visual science; Pharmacology and drug therapy in eye diseases; Basic Sciences; Primary and Secondary eye care; Patient Safety and Quality of Care Improvements. This journal is indexed on

Submit your manuscript here: http://www.dovepress.com/clinical-ophthalmology-journal

\section{Dovepress}

PubMed Central and CAS, and is the official journal of The Society of Clinical Ophthalmology (SCO). The manuscript management system is completely online and includes a very quick and fair peer-review system, which is all easy to use. Visit http://www.dovepress.com/ testimonials.php to read real quotes from published authors. 